\title{
OP01
}

\section{CHANGE OF PERCEIVED CHROMA AND HUE OF OBJECT COLOURS AT DIFFERENT LIGHTING LEVELS DUE TO HUNT EFFECT}

\author{
Yuki Kawashima \& Yoshi Ohno
}

DOI 10.25039/x47.2020.OP01

\section{Paper accepted for the $5^{\text {th }}$ CIE Symposium on Colour and Visual Appearance}

The paper was selected by the International Scientific Committee (ISC) for presentation at the 5th CIE Symposium on Colour and Visual Appearance, Hong Kong, CN, April 21-22, 2020, which, due to the corona pandemic, could not take place. The paper has not been peer-reviewed by CIE.

\section{(C) CIE 2020}

All rights reserved. Unless otherwise specified, no part of this publication may be reproduced or utilized in any form or by any means, electronic or mechanical, including photocopying and microfilm, without permission in writing from CIE Central Bureau at the address below. Any mention of organizations or products does not imply endorsement by the CIE.

This paper is made available open access for individual use. However, in all other cases all rights are reserved unless explicit permission is sought from and given by the CIE.

CIE Central Bureau

Babenbergerstrasse 9

A-1010 Vienna

Austria

Tel.: +4317143187

e-mail: ciecb@cie.co.at

www.cie.co.at 


\title{
OP01
}

\section{CHANGE OF PERCEIVED CHROMA AND HUE OF OBJECT COLOURS AT DIFFERENT LIGHTING LEVELS DUE TO HUNT EFFECT}

\author{
Kawashima, Y., Ohno, Y. \\ National Institute of Standards and Technology, Gaithersburg, MD USA \\ yuki.kawashima@nist.gov
}

\begin{abstract}
Our previous study made an attempt to quantify the perceived chroma changes due to Hunt Effect in lighting for red and green colour samples. For further understanding of Hunt Effect, another vision experiment was conducted using a number of red, green, yellow and blue colour samples to quantify perceived chroma changes as well as hue angle changes at different lighting levels. A reference patch was placed on one side of booth at $100 \mathrm{~lx}$, and 20 to 25 test patches with varied chroma and hue levels were placed on the other side of the booth at $1000 \mathrm{Ix}$. Subjects viewed each booth with each eye separately (haploscopic view) and chose a test patch that appeared to be closest to the reference patch. Results showed that the chroma at $100 \mathrm{Ix}$ was perceived $8 \%$ to $15 \%$ lower compared to the chroma at $1000 \mathrm{~lx}$, and the hue angles also shifted slightly in different directions for different colours.
\end{abstract}

Keywords: Hunt Effect, colour fidelity, chroma, lighting, haploscopic view

\section{Introduction}

It is known that light level can affect perceived chroma of objects, and this effect is called Hunt Effect (Hunt, 1950). According to the Hunt Effect, objects at indoor lighting would appear less saturated than at outside daylight, which is generally at much higher light level than the indoor lighting. Our previous experiment using lighting levels at $100 \mathrm{Ix}$ and $1000 \mathrm{Ix}$ verified that the Hunt Effect is effective at light levels for the normal indoor lighting (Kawashima and Ohno, 2019a).

In order to make the colour appearance of objects at the indoor lighting close to that at the daylight, chroma of the object colours need to be increased by the lighting. The perceived chroma of the objects has been related to colour preference and memory. Previous studies suggest that preferred colours of the objects are more saturated than the actual colours (Judd, 1967; Thornton, 1974). For example, Caucasian skin is preferred to be redder than it really is (Sanders, 1959). Furthermore, it was showed that the object colour is memorized to have more saturated colour than the actual colour (Bartleson, 1961; Newhall et al., 1957). However, if Hunt Effect is considered, and if the outside daylight is considered as the reference for the colour appearance of objects, increasing the object chroma by lighting would bring higher colour fidelity, and it would become a matter of colour fidelity. In current colour fidelity metrics, CRI (CIE, 1995) or CIE Colour Fidelity Index (CIE, 2017; IES, 2015), any changes of chroma (increase or decrease) from the reference illuminant is equally penalized, thus a new fidelity metric taking this effect into account will be needed.

Therefore, it is important to quantify the degree in which the Hunt Effect affects the perception of colour saturation and evaluate impact on colour fidelity. Our previous experiment quantified the chroma change for red and green samples due to the Hunt Effect (Kawashima and Ohno, 2019b). However, it is still not clear how much perceived chroma shifts occur on other colours by Hunt Effect, e.g. blue and yellow. In addition to the Hunt Effect, it is known that the light level can affect the perceived hue (Bezold-Brucke effect, von Bezold, 1873). Thus, the magnitude of perceived hue shifts as well as chroma change needs to be quantified when Hunt Effect is to be considered in colour rendering metrics.

Therefore, the purpose of this study is to quantify the changes of perceived chroma and hue for four fundamental colours - red, green, yellow, and blue. 


\section{Methods}

A colour-matching experiment was conducted using a double-booth with 16 channel spectrally tuneable light sources. One side of the double-booth was set at $100 \mathrm{Ix}$ and the other side at $1000 \mathrm{Ix}$. A reference patch was placed on the booth at $100 \mathrm{~lx}$, and a number of test patches with varied chroma and hue levels were placed on the other side of the booth at $1000 \mathrm{Ix}$. The subject was adapted in haploscopic view condition, so his/her left eye was adapted to the leftside booth and the right eye to the right-side booth. The subject was asked to choose a matching test patch that appeared closest to the reference patch.

Since each eye will not be perfectly adapted to very different light levels with the haploscopic view, it was first tested for how completely the subject was adapted to each light using grey patches before starting the colour matching experiment. After the subject was fully adapted to each light in haploscopic condition, a reference grey patch was placed on one side of the booth at $1000 \mathrm{Ix}$ and five test grey patches having several different lightness levels were placed on the other side of booth at $100 \mathrm{Ix}$. The reference grey patch was the same as the darkest one among the test grey patches. The subject chose a test grey patch that matched the brightness of the reference grey patch. If adaptation of each eye to each light level is perfect, the test grey patch with the same grey level as that of reference grey patch would be chosen. If adaptation is not complete, a lighter grey test patch will be chosen. The difference between the grey level of the matching test patch and the reference grey patch represents incompleteness of the adaptation, which was used to correct the experiment results.

\subsection{Apparatus}

A double-booth with spectrally tuneable light sources shown in Figure 1 was used for the experiment. The double-booth has a viewing compartment and a light source compartment (see the right figure), and is divided into left and right by a partition wall at its centre (left figure). The light source compartment was hidden by a top cover during the experiment and the subject did not see the light source directly. A view divider is attached to the centre partition wall for the haploscopic view. The inside of the viewing compartment and the centre partition wall are painted in grey. The size of viewing area on each side is $50 \mathrm{~cm}$ wide, $65 \mathrm{~cm}$ deep, and $37 \mathrm{~cm}$ high (in front window). Each side of the light source compartment is equipped with a spectrally tuneable light source which has 16 channels of LED spectra (ranged from $495 \mathrm{~nm}$ to $730 \mathrm{~nm}$ peak). The spectrum of the light source is controlled with a computer program that can change intensity for each channel. The light-emitting surface of the light source is a diffuser of $10 \mathrm{~cm}$ diameter, and there is a large light-transmitting diffuser between the light source compartment and the viewing compartment in the booth, with which good spatial colour uniformity is provided in the viewing area.
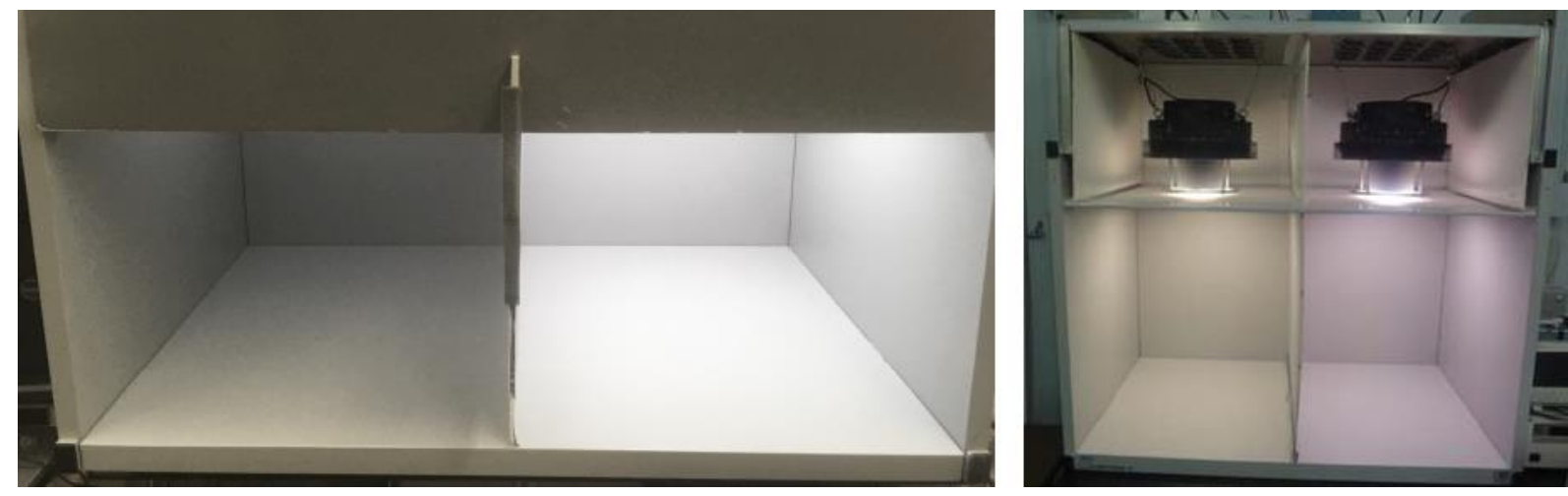

Figure 1 - Photograph of the double-booth.

The light sources need a long time (several hours) to stabilize completely. Therefore, the light sources were kept turned on all the time during the experiment period, and was set to initial condition of the experiment ( $3000 \mathrm{~K}$ or $6500 \mathrm{~K}, 1000 \mathrm{Ix}$ and $100 \mathrm{Ix}$ for each side) at least one hour prior to starting the experiment. All the spectral distributions used in the experiment were measured before and after the experiment every day, at the bottom surface of the booth at $\approx 10 \mathrm{~cm}$ from the partition wall, and $\approx 25 \mathrm{~cm}$ from the front edge of the booth. The measured 
chromaticity differences between the booth at $1000 \mathrm{Ix}$ and $100 \mathrm{Ix}$ of same CCT settings were set and kept within 0.0035 in $\Delta u^{\prime} v$ ' (in most cases within 0.002 with maximum 0.0035 ) during experiments.

The expanded uncertainties $(k=2)$ of the measurements were estimated to be 0.0012 in $u$ ', 0.0011 in $v^{\prime}, 0.0009$ in Duv, $17 \mathrm{~K}$ in CCT at $3000 \mathrm{~K}$ and $52 \mathrm{~K}$ at $6500 \mathrm{~K}$ for the light spectra used in this experiment. The expanded uncertainty in the relative chromaticity measurement between each pair of light was 0.0002 in $u^{\prime}$ and $v^{\prime}$, which is the typical repeatability of the instrument. The expanded uncertainty of illuminance of the spectroradiometer is estimated $3 \%$ $(k=2)$ for directional incident light, and its uncertainty for relative measurement was $0.2 \%$, which is the typical reproducibility of the instrument.

\subsection{Colour patches and light sources}

All patches used in this experiment were produced with a thick matte paper printed with a special professional printer. The colours of patches were adjusted by repeated measurements and re-printing.

Six grey patches $(5.4 \mathrm{~cm} \times 5.4 \mathrm{~cm})$ were used for grey scale matching. The five grey patches were used as the test grey patches on the booth at $100 \mathrm{~lx}$ and have five different lightness $\left(J^{\prime} \approx 75\right.$ to 80 , or reflectance $49 \%$ to $57 \%$ ). The reference grey patch, identical to the darkest grey test patch, was placed on the other side of booth at $1000 \mathrm{Ix}$.

Four sets of colour patches, red green, yellow and blue, were used for the colour matching experiment. Each set consisted of a reference colour patch and 19 to 25 test colour patches with different chroma and hue levels. The size of each patch was $6.4 \mathrm{~cm} \times 6.4 \mathrm{~cm}$. The reference patches were identical to the most saturated test patch in each colour. Figure 3Error! Reference source not found. shows the photographs of all the test colour patches, and Figure 3 shows the (a', b') colour coordinates of these colour patches on CIECAM02 colour space under D65 lighting. The range of chroma difference was $\Delta C_{a^{\prime} b^{\prime}} \approx 12$ with intervals of $\Delta C_{a^{\prime} b^{\prime}} \approx 3$ for each colour. The range of hue angles was $\approx 12^{\circ}$ for red, $9^{\circ}$ for yellow and blue, with intervals of $3^{\circ}$ for these colours, and $15^{\circ}$ for blue with intervals $5^{\circ}$. The interval for blue patch was different because $3^{\circ}$ was perceived too small. The colour coordinates of the reference patches are indicated by " $X$ " in Figure 3. The reference patch was not necessarily at the edge of the hue range and not always the same side. The ranges of the hue shift of test patches relative to the reference patch were determined by preliminary experiments. As shown in Figure 2Error! Reference source not found., each set of the test patches were placed in four or five rows by five columns, for different chroma levels at each row and different hue angle shifts for each column. One position in yellow and blue is missing because these colour coordinates could not be produced by the printer. The set of test patches for each colour was put on a grey plate so that the set could be easily replaced by other colours. 

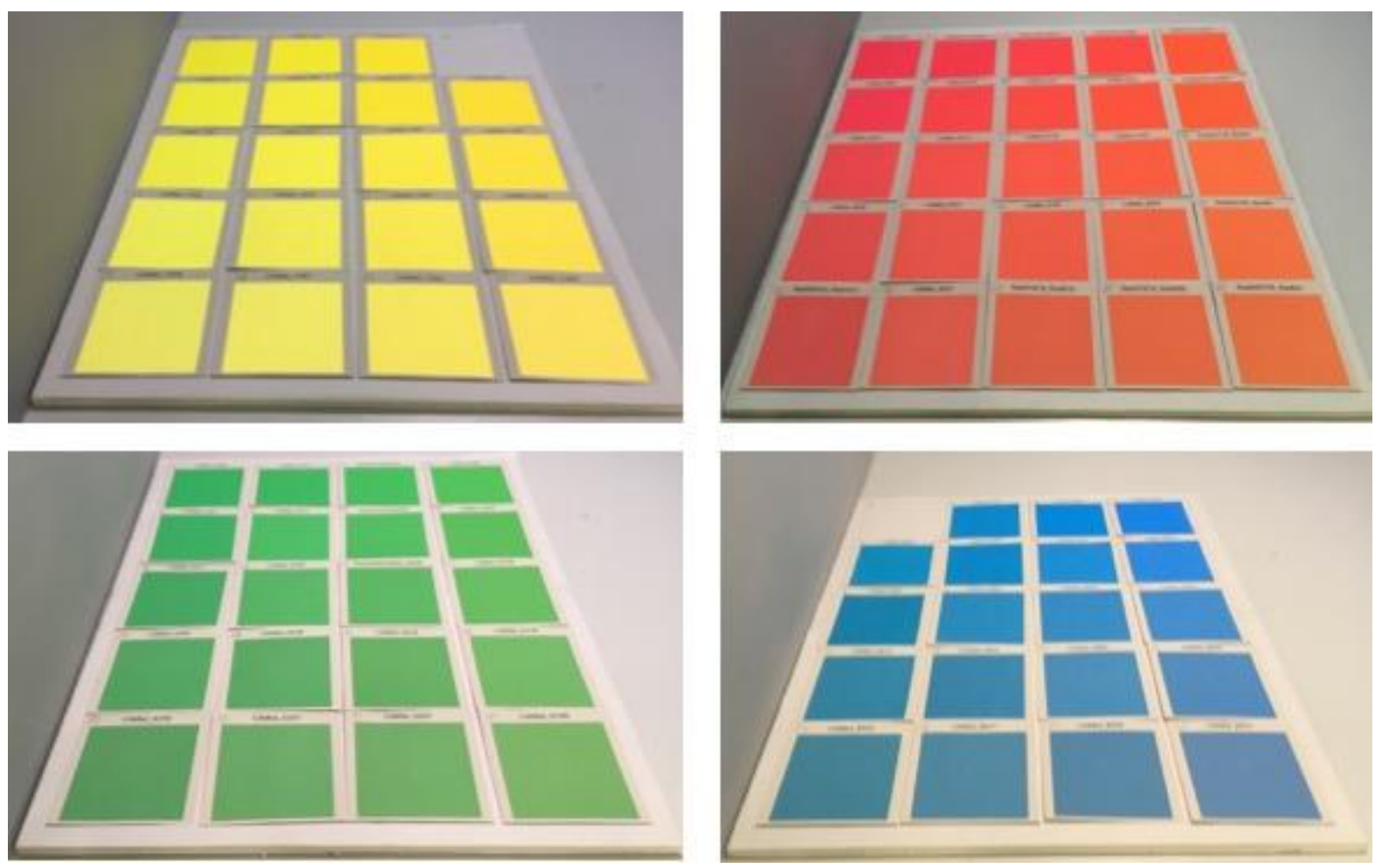

Figure 2 - Photograph of the test colour patches.

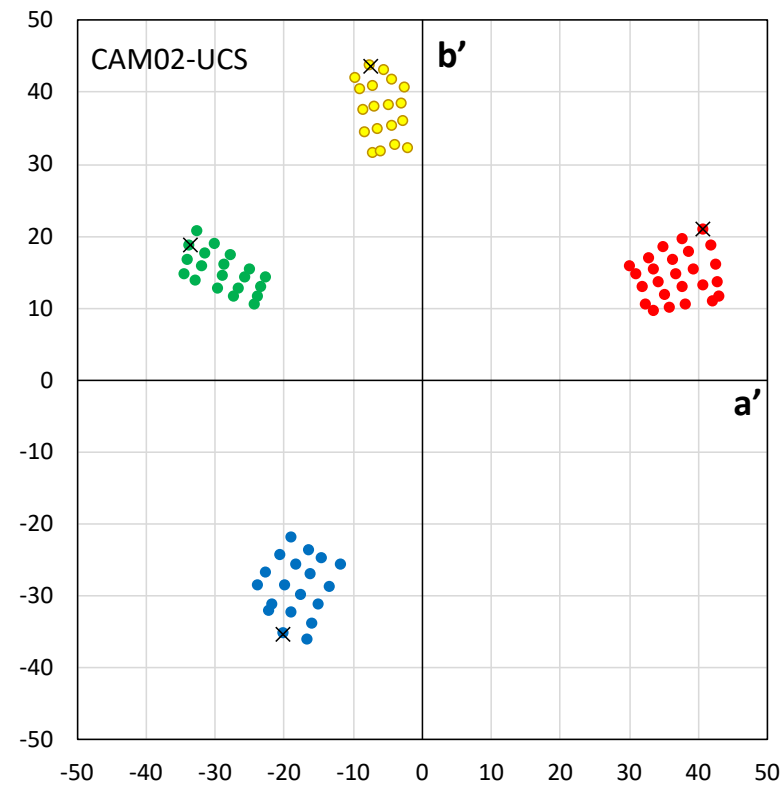

Figure 3 - Colour coordinates of the colour patches on CIECAM02. X marks show the reference patches

Each patch was placed at near the centre partition wall and its centre was $\approx 25 \mathrm{~cm}$ from the front edge of the booth. The subject observed the patches at a viewing angle of approximately $45^{\circ}$ from the normal to the patch surface, and the viewing distance between the targets and subject's eye was $\approx 48 \mathrm{~cm}$. The spectral reflectance of all the patches was measured prior to the experiment, using a telephoto-type spectroradiometer in comparison to a white reference standard. 
The lights for both sides were set at the same CCT, $3000 \mathrm{~K}$ or $6500 \mathrm{~K}$, with Duv $=0$ using broadband spectra. The left side of the booth was set at $1000 \mathrm{~lx}$ and the right side was set at $100 \mathrm{Ix}$; and the sides were revered in some conditions. Thus, both illuminance levels were prepared for each side of booth. Figure 4 shows the spectra of the lights used in left and right side of the booths. The spatial nonuniformity in chromaticity u', v' over the area of all test patches on the grey plate under illumination of the $1000 \mathrm{~lx}$ lights, were within 0.001 for both CCTs.
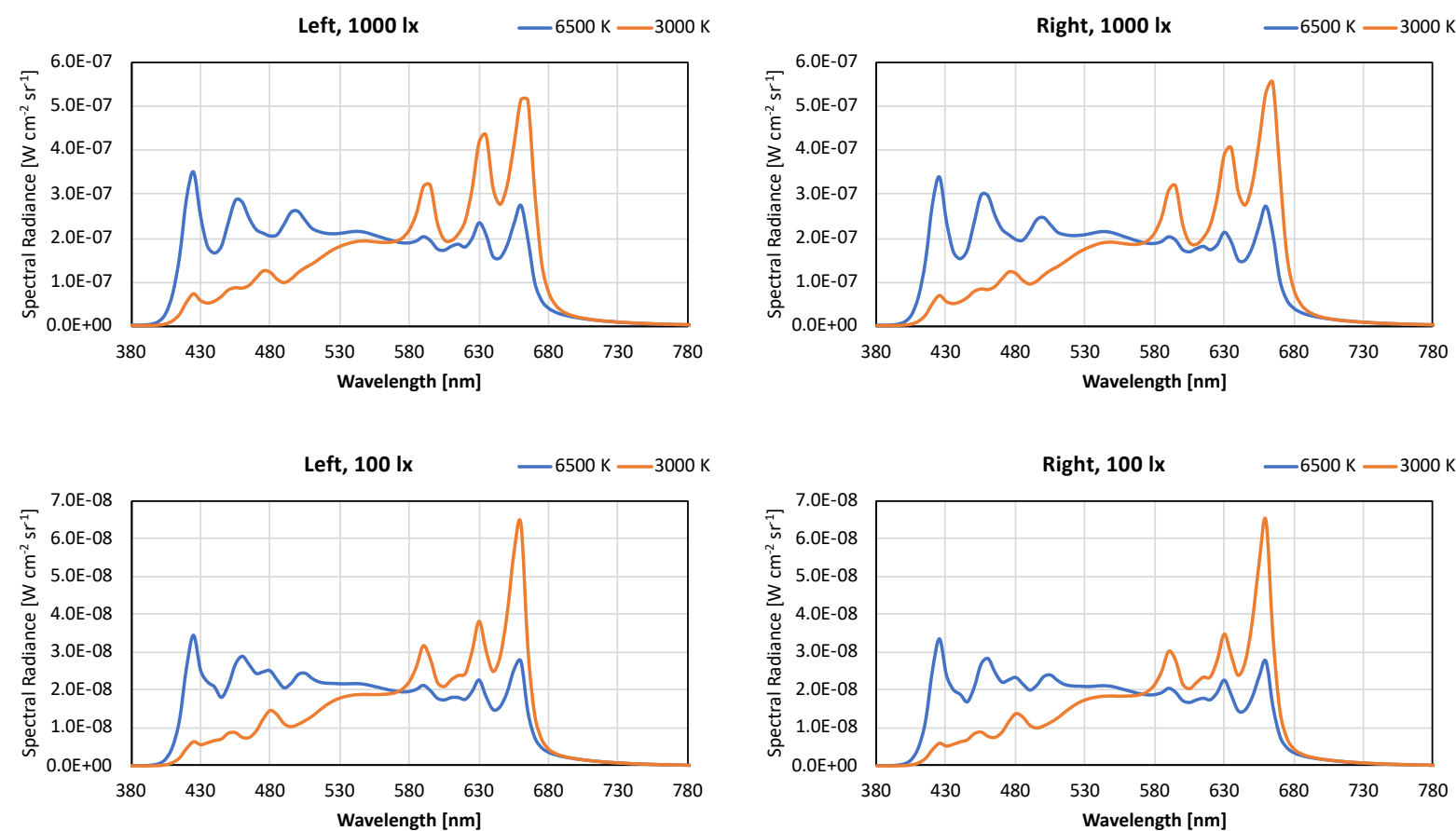

Figure 4 - The spectral distributions of the lights at $1000 \mathrm{~lx}$ and $100 \mathrm{~lx}$ for each CCT

\subsection{Procedures}

Each subject was tested for normal colour vision using Ishihara Test before starting the experiment. The subject was instructed to be seated in front of the booths and viewed the booths with his/her forehead and nose placed against the view divider (haploscopic view) as shown in Figure 5. With the haploscopic view, the left eye viewed only the left side booth, and the right eye viewed only the right side both.

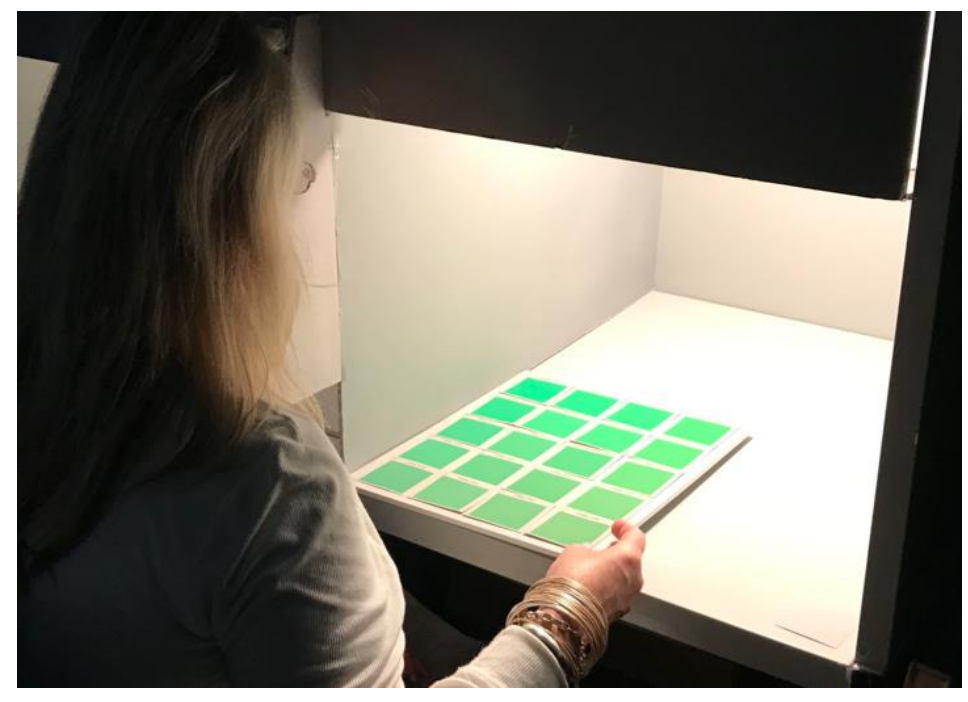

Figure 5 - Experimental scene of the haploscopic view 
The colour matching experiment consisted of four sessions according to the CCT condition and the illuminance combination. The illuminance combinations were same in the first two sessions and then switched to the other for next two sessions. The order of the illuminance combination was randomized for each subject. The CCT condition was also used in random order for each of the two sessions with same illuminance combination. In each session, the subject conducted the colour matchings for four colours in random order.

Before starting each session, the subject adapted to each light with each eye. The adaptation time was three minutes for the first and third sessions, or one minutes for the second and fourth sessions. An instruction for the experiment was given to subjects during the adaptation for the first session. After the adaptation, the grey patches were placed in the booths, and the subject conducted the grey scale matching. The results of this grey matching were used to correct the experimental results for imperfect adaptation with the haploscopic view. the subject was asked to select one of grey patches on the booth at $100 \mathrm{~lx}$ that matched the brightness of the other side.

After finishing the grey scale matching, grey patches were removed. Then, a set of colour patches, the reference patch and test patches, were placed in the booths, covered by the grey plates. The reference colour patch was placed on the booth at $100 \mathrm{Ix}$, and the test colour patches were placed on the booth at $1000 \mathrm{Ix}$. One minute later, the experimenter removed the grey plates and the subjects chose a matching test patch closest to the reference patch. When choosing a matching patch, the subjects were allowed to slide the test patches back and forth to compare with the reference patch. After choosing a matching test patch, the colour patches were replaced with the next set of colour patches.

\subsection{Observers}

A total of 22 subjects participated in this experiment. All subjects have normal colour visions as tested using Ishihara Test. They were 11 males and 11 females with their ages from 18 to 64 years old, consisting of 19 Caucasians, two Blacks and one native American. They were summer-internship students or NIST employees, who were not experts on colour or lighting and completely naïve as to the purpose of the experiment.

\section{Results}

Figure 6 shows the a', b' coordinates of the patches calculated under the light at each CCT on CIECAM02 colour space. The coloured circles are the patches chosen by at least one subject. In most cases the subjects chose the test patches with lower chroma and slightly different hue angles from the reference patches. The mean coordinate for the matching patches is marked as black-filled circle with error bars. It was found that not only the chroma of the chosen matching patches decreased but also hue angle shifted from the reference patch. 
$3000 \mathrm{~K}$

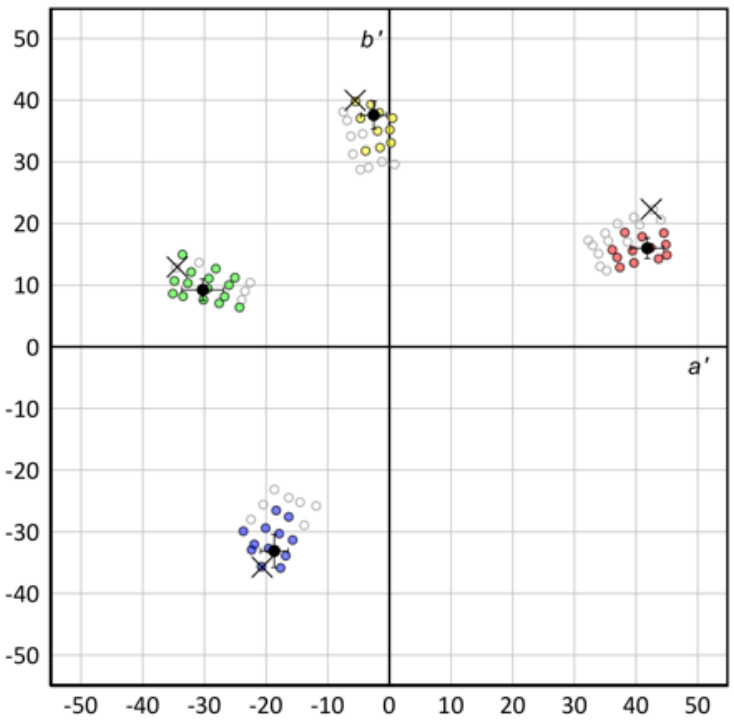

$6500 \mathrm{~K}$

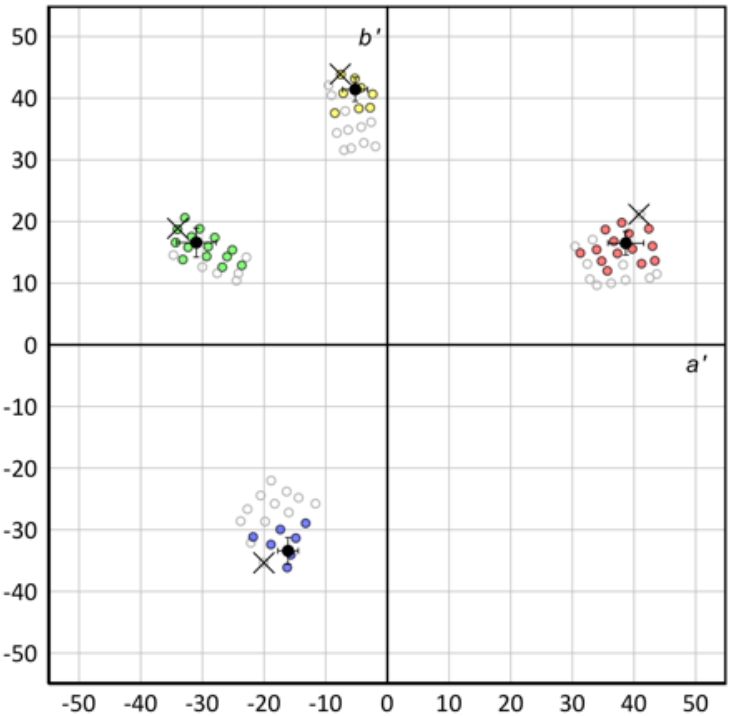

Figure 6 - Colour coordinates for the patches with the light at $3000 \mathrm{~K}$ (left) and $6500 \mathrm{~K}$ (right) on CIECAM02. $X$ marks show the reference patches and circles show the test patches. The coloured circles are the patches chosen by subjects. The black-filled circles with error bar are the mean coordinate for matching patches of each colour. Error bar shows the standard deviation

The results of the grey matching were used to correct the experimental results for imperfect adaptation in the haploscopic condition. Typically, patches of J' $\approx 75$ to 77 (where the reference was $\mathrm{J}^{\prime}=75$ ) were chosen by the subjects, indicating some individual variations. In order to correct the chroma of the colour patch based on the grey scale matching, the J' increase from the reference grey patch was used. First, chroma change of the matching patch was calculated as a function of the $\mathrm{J}$ 'increase by multiplying the spectral reflectance. Then, the chroma change for the $\mathrm{J}$ ' increase for the chosen matching grey patch was used as a correction value of the chroma change for the matching patch.

Chroma differences between the chosen matching patch and the reference patch in each colour were calculated for each CCT condition. These chroma differences were normalized by chroma of the reference for each colour and CCT, and expressed as relative change in \% of chroma, since the chroma of the references were different for each colour and CCT. Figure 7 shows the mean relative chroma differences for each colour and CCT, corrected for the grey matching results. The mean chroma of the chosen matching patch was $8 \%$ to $15 \%$ lower than the reference patch at $3000 \mathrm{~K}$, and $8 \%$ to $12 \%$ lower at $6500 \mathrm{~K}$, depending on colour of patches. The difference was largest for green and smallest for yellow. A two-factor Analysis of Variance (ANOVA) was conducted to test the effect of patch colour and CCT. A main effect ${ }^{*}$ of CCT was not found $(F(1,21)=1.02, p=0.32)$ meaning that there is no statistically significant effect of CCT. However, a main effect ${ }^{\star}$ of patch colour was found $(F(3,63)=8.13, p<0.01)$, which means that the patch colour affects the results among the conditions. Further, there was also an interaction* between the patch colour and CCT $(F(3,63)=7.38, p<0.01)$, which means that the chroma differences occurred depending on combinations of the conditions.

\footnotetext{
* "Main effect" and "interaction" are terms for ANOVA (Chambers and Hastie, 1992).
} 


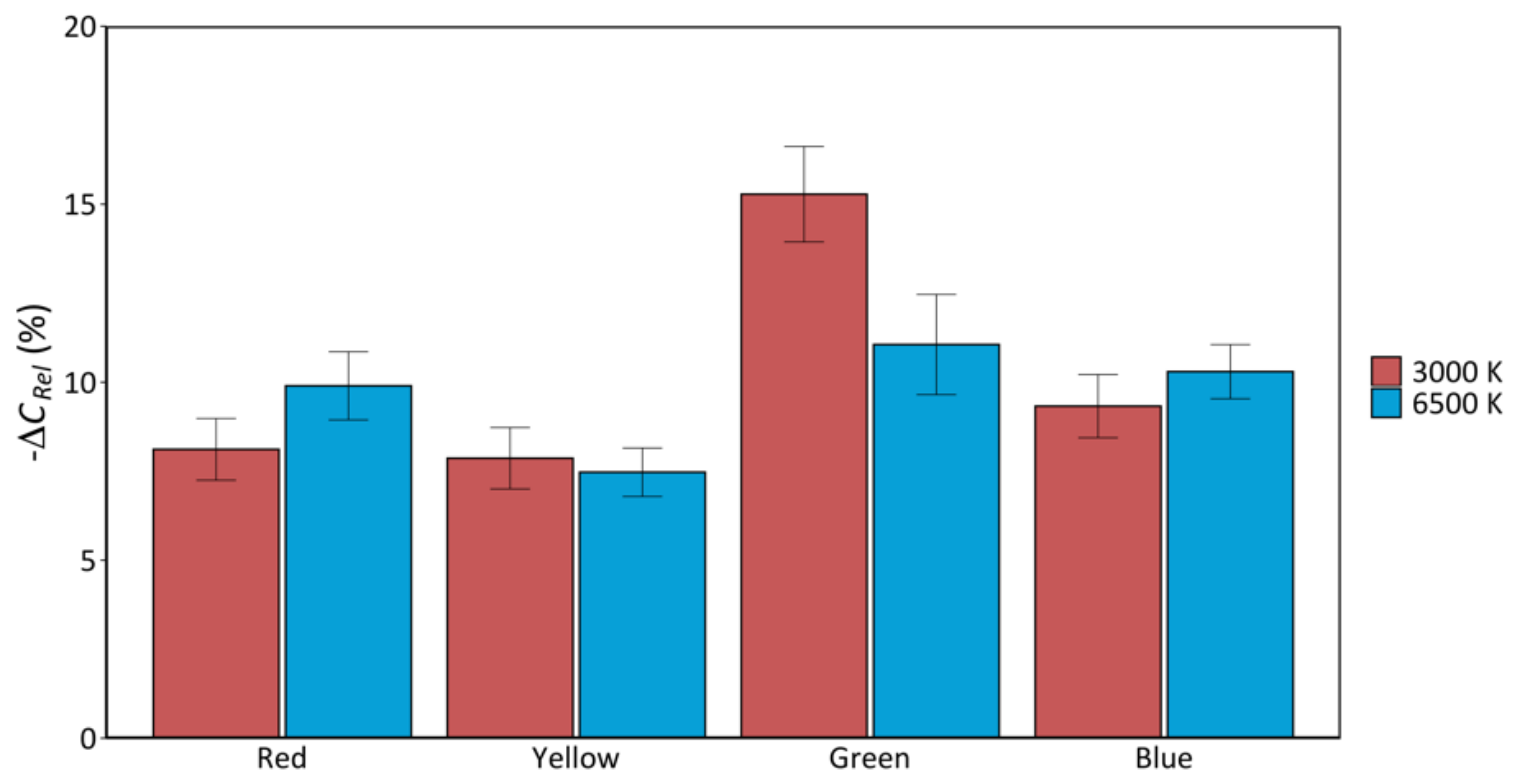

Figure 7 - Relative chroma differences for $3000 \mathrm{~K}$ and $6500 \mathrm{~K}$. Each bar shows the normalized mean chroma difference between the reference and chosen matching patch. Error bar shows the standard error.

Hue differences were also calculated for each colour and CCT as shown in Figure 8 The changes in hue angle was from $-7^{\circ}$ to $4^{\circ}$ in both CCTs, and the change was most significant in red $-7^{\circ}$ at $3000 \mathrm{~K}$. Small changes in the hue angle were seen at $6500 \mathrm{~K}$ and $3000 \mathrm{~K}$ for green and blue, respectively. Furthermore, red and yellow, and green and blue, respectively changed in the same direction.

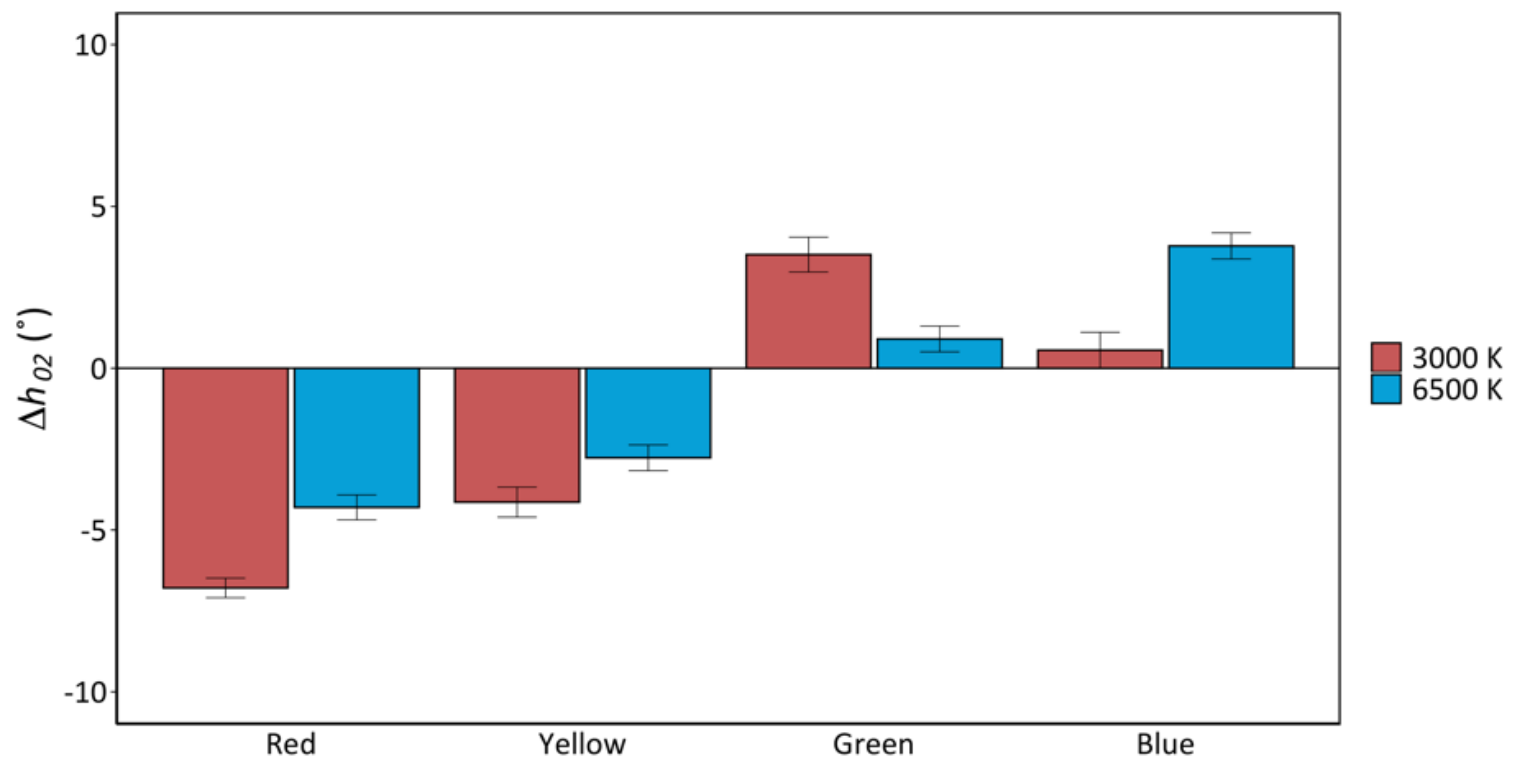

Figure 8 - Hue differences for $3000 \mathrm{~K}$ and $6500 \mathrm{~K}$. Error bar shows the standard error.

\section{Conclusions}

The changes in perceived chroma and hue angle between $100 \mathrm{Ix}$ and $1000 \mathrm{Ix}$, by Hunt Effect have been quantified for four different colours. It has been verified that perceived chroma decreases significantly for all four colours in these conditions. As in previous experiments, the green patch showed a greater change in chroma than the red patch. It was also found that yellow and blue had similar chroma change as red. Furthermore, the direction and magnitude 
of perceived hue shifts at a lower illuminance level have been quantified. These results may be useful to develop a new colour fidelity model incorporating the Hunt Effect. Further experiments at more different lighting levels are desired.

\section{Acknowledgement}

The authors thank Semin Oh at Ulsan National Institute of Science and Technology, South Korea, for his valuable contributions in preparing and assisting the vision experiment at NIST. The experiment using human subjects in this study was conducted under NIST Institutional Review Board approval PML-16-0001.

\section{References}

BARTLESON, C.J. 1961. Color in Memory in Relation to Photographic Reproduction. Photogr. Sci. Eng., 5(6), 327-331.

CHAMBERS, J.M., HASTIE, T.J. (Eds.) 1992. Statistical Models in S. New York: Chapman and Hall/CRC. DOI: 10.1201/9780203738535

CIE 2017. CIE 224:2017. CIE 2017 Colour Fidelity Index for Accurate Scientific Use. Vienna: Commission Internationale de l'Eclairage.

CIE 1995. CIE 013.3-1995. Method of Measuring and Specifying Colour Rendering Properties of Light Sources. Vienna: Commission Internationale de l'Eclairage.

HUNT, R.W.G. 1950. The Effects of Daylight and Tungsten Light-Adaptation on Color Perception. J. Opt. Soc. Am., 40(6), 362-371. DOI: 10.1364/JOSA.40.000362

IES 2015. ANSI/IES TM-30-15. IES Method for Evaluating Light Source Color Renditon. New York: Illuminating Engineering Society of North America.

JUDD, D.B. 1967. The Flattery Index for Artificial Illuminants. Illum. Eng., 62(10), 593-598.

KAWASHIMA, Y., OHNO, Y. 2019a. VISION EXPERIMENT ON VERIFICATION OF HUNT EFFECT IN LIGHTING, in: PROCEEDINGS OF the 29th Quadrennial Session of the CIE. International Commission on Illumination, CIE, 496-504. DOI: 10.25039/x46.2019.OP68

KAWASHIMA, Y., OHNO, Y. 2019b. QUANTIFYING PERCEIVED CHROMA CHANGES BY HUNT EFFECT IN LIGHTING, in: PROCEEDINGS OF the 29th Quadrennial Session of the CIE. International Commission on Illumination, CIE, 698-705. DOI: 10.25039/x46.2019.PP06

NEWHALL, S.M., BURNHAM, R.W., CLARK, J.R. 1957. Comparison of Successive with Simultaneous Color Matching. J. Opt. Soc. Am., 47(1), 43. DOI: 10.1364/JOSA.47.000043

SANDERS, C.L. 1959. Color Preference for Naural Objects. Illum. Eng., 54(7), 452-456.

THORNTON, W.A. 1974. A Validation of the Color-Preference Index. J. Illum. Eng. Soc., 4(1), 48-52. DOI: 10.1080/00994480.1974.10732288

VON BEZOLD, W. 1873. Ueber Das Gesetz Der Farbenmischung Und Die Physiologischen Grundfarben. Ann. der Phys. und Chemie, 226(10), 221-247. DOI: 10.1002/andp.18732261004 